\title{
Antimicrobial Effects of FolkMedicinal Plants From the North of Iran Against Mycobacterium tuberculosis
}

\author{
Shadi Jahanpour ${ }^{1}$; Kiumars Ghazisaidi ${ }^{1}$; Homa Davoodi ${ }^{1}$; Masoumeh Mazandarani ${ }^{2}$; \\ Motahare Samet ${ }^{1}$; Nadia Jahanpour ${ }^{3}$; Ezzat Allah Ghaemi ${ }^{1, *}$ \\ ${ }_{1}^{1}$ Infectious Disease Research Center, Golestan University of Medical Sciences, Gorgan, IR Iran \\ ${ }^{2}$ Islamic Azad University, Gorgan Branch, Gorgan, IR Iran \\ 3 Islamic Azad University, Lahijan Branch, Lahijan, IR I \\ ${ }^{*}$ Corresponding author: Ezzat Allah Ghaemi, Infectious Disease Research Center, Golestan University of Medical Sciences, Gorgan, IR Iran. Tel: +98-9113711770, Fax: +98-1732245597, \\ E-mail:eghaemi@yahoo.com
}

Received: February 9, 2014; Revised: May 18, 2014; Accepted: August 23, 2014

\begin{abstract}
Background: Medicinal plants have been used traditionally in Golestan province(north of Iran), against Mycobacterium tuberculosis or the clinical signs of tuberculosis (TB).

Objectives: This study aimed to define the inhibitory effects of ethanolic extracts of six of these medicinal plants against Mycobacterium tuberculosis.

Materials and Methods: Peganum harmala (seed extract), Punica granatum (peel extract), Digitalis sp. (leaf extract), fruit extract of Citrus lemon, Rosa canina and Berberis vulgaris were extracted in ethanol and their activity against M. tuberculosis isolates were determined by the agar diffusion method. The zone of inhibition (at 200 to $1.6 \mathrm{mg} / \mathrm{mL}$ ) was measured and the results were compared with isoniazid and rifampin as standard positive controls. Also the concentration of vitamin C of each the extracts was evaluated.

Results: The ethanolic extract of Peganum harmala seed and Punica granatum peel exhibited potential activity against all M. tuberculosis isolates with mean inhibitory zone of 18.7 and $18.8 \mathrm{~mm}$, at $200 \mathrm{mg} / \mathrm{mL}$ concentration. The mean inhibitory zone around isoniazid and rifampinwere 19.2 and $18.8 \mathrm{~mm}$. Ethanolic extract of Citrus lemon showed moderate inhibitory activity only against sensitive (non MDR; non multi drug resistant) strains of $M$. tuberculosis, and Digitalis sp. showed inhibitory effects on five isolates. Ascorbic acid content was 43.3 $\mathrm{mg} / \mathrm{dL}$ in Punica granatum and Digitalis sp. and only $9.1 \mathrm{mg} / \mathrm{dL}$ in ethanolic extract of Peganum harmala.

Conclusions: The highest content of vitamin C was observed in the extract of Punica granatum, which was observed to be highly active against Mycobacterium tuberculosis, while the $P$. harmala must have contained other phytochemical constituents that contributed to the anti-tuberculosis effects of this plant. Our findings showed that ethanolic extracts of P. granatum and P. harmala had anti-TB effects comparable to isoniazid and rifampin and can be good candidates for novel and safe natural products against tuberculosis.
\end{abstract}

Keywords: Medicinal Plants; Mycobacterium tuberculosis; Vitamin C; In Vitro

\section{Background}

Tuberculosis (TB) is one of the major fatal infectious diseases in the world (1). It has infected one-third of the world's population and is responsible for approximately 2 million deaths each year, mostly in developing countries (2). In 2010, approximately 8.8 million new cases of active TB was reported and 1.1 million people died from the disease, most of which happened in developing countries (3). Tuberculosis typically affects the lungs and spreads from an infected person to a susceptible person (4). This infection requires a long duration of therapy, which is six months for first-line drugs, including isoniazid, rifampin, ethambutol and pyrazinamide (5). In certain situations (for example, bacterial drug resistance and intolerance), second-line drugs are used, mostly based on high-risk medications, such as fluoroquinolones, capreomycin, ethionamide and cycloserine, that are usually less effective and more toxic with side ef- fects for the patient (6). The improper use of these drugs results in increasing prevalence of multi-drug resistant (MDR) and extensively drug resistant (XDR) strains of $M$. tuberculosis that are resistantto both first and second-line drugs (7). Therefore there is an urgent need to search for complementary medicines or new alternatives of antibiotics, especially from natural sources, which work more effectively with fewer side effects $(8,9)$. Medicinal plants have been used for this purpose in many countries to prevent and treat infectious diseases (10). Antioxidants such as vitamin $\mathrm{C}$, tocopherols, carotenoids, polyphones and flavonoids may be responsible for the antibacterial activity of medicinal plants. Many studies have found an association between anti-tuberculosis activity of medicinal plant extracts and their vitamin $C$ content, which can be an importantfinding (11). Tuberculosis has been a threatening disease in Iran from the distant past. According to 
the world health organization, the estimated incidence rate of TB in the Islamic Republic of Iran was 21 cases per 100000 people in 2011. The Golestan province, located in the south-east of the Caspian sea has the highest incidence of TB in Iran (12). This province due to its diverse climatic and heterogeneous ecological condition is able to grow many plants, especially medicinal plants, and the search for finding medicinal plants that inhibit the growth of Mycobacterium tuberculosis is of great importance in this region.

\section{Objectives}

The present study aimed to investigate the anti-M. $t u$ berculosis activity of six medicinal plants in the region against Mycobacterium tuberculosis for the management of the tuberculosis disease.

\section{Materials and Methods}

\subsection{Preparation of Plant Samples}

Six medicinal plants were selected for the present study. The selected plants namely Citrus lemon (Rutaceae), Peganum harmala (zigophyllaceae), Punica granatum (Lythraceae), Rosa canina (Rosaceae), Berberis vulgaris (Berberidaceae), Digitalis sp. (Scrophulariaceae) had shown anti-mycobacterial activity against non-pathogenic mycobacteria in a previous study (13). The selected plants were collected from ranges as high as $650-2250 \mathrm{~m}$ and from three regions Ziaret, Deraznoo and Charbagh, located south of Golestan province from July to September 2012. Table 1 presents the scientific name, local names and their uses in traditional medicine.

The method of Alade and Irobi (14) was used for the extraction of plant extracts with minor modifications. Briefly the plants were air-dried in the dark at room temperature and then ground into fine powder using an electric blender. Plant hydro-alcoholic extracts were prepared by the maceration method; $30 \mathrm{~g}$ of each dried powder was soaked in $100 \mathrm{~mL}$ of $70 \%$ ethanol for 72 hours. A sterile glass rod was used for stirring each mixture every 24 hours. The plant extracts were filtered twice through Whatman filter paper no. 1 (Whatman, UK). The obtained filtrates were evaporated using a rotary evaporator. The final products were sticky-brown substances and stored in a laboratory refrigerator prior to the test. The concentrated extract was freshly dissolved in dimethyl sulfoxide (DMSO) before use.

\subsection{Preparation of Inoculums}

In the present study a total of seven isolates of Mycobacterium tuberculosis were used; six clinical isolates were identified by conventional methods including two MDR and four sensitive isolates to rifampin and isoniazid, which were isolated from sputum of tuberculosis patients in Gorgan. Also a drug-susceptible strain of $M$. tuberculosis (H37Rv), which was sensitive to rifampin and isoniazid, was kindly provided by Dr. Hashemi (Ahvaz University of Medical Sciences, Ahvaz, Iran). The bacterial cultures, which were used to prepare the standard inoculums, were maintained on Lowenstein-Jensen medium (Merck). A suspension of each bacterium was prepared in normal saline containing 0.05\% Tween-80 and adjusted approximately to McFarland 0.5 standard (15).

\subsection{Anti M. tuberculosis Activity}

Antibacterial activity was determined by the disk diffusion method $(16,17)$. One hundred microliters of mycobacterial suspension was spread onto the surface of Lowenstein Jenson media, using a sterile glass spreader. The extracts were dissolved in $2 \%$ DMSO (Sigma) to obtain a concentration of $200 \mathrm{mg} / \mathrm{mL}$ and further diluted to their final concentrations. The final concentration of DMSO in all assays was $2 \%$ or less, which is nontoxic for mycobacteria (18). Sterile paper disks (6 mm diameter) were loaded with $40 \mu \mathrm{L}$ of extract (varying concentrations: 200, 100, $50,25,12.5,6.25,3.12$ and $1.6 \mathrm{mg} / \mathrm{mL}$ ) and then left to dry. The impregnated-disks were then placed on the surface of plates on which the microorganisms were cultured. Rifampin (MAST) and Isoniazid (SIGMA-ALDRICH) was used as the positive control and disks treated with $2 \%$ DMSO were used as the negative control. The culture plates were sealed in plastic bags and incubated at $37^{\circ} \mathrm{C}$ for three weeks, after which culture-growth was clearly visible on the agar. The clear zone visible all around the

\begin{tabular}{|c|c|c|c|c|c|}
\hline Plants & Local Name & Family & Part(s) Used & Preparation Used & Therapeutic Use \\
\hline Citrus lemon & Limoo & Rutaceae & fruit pulp & $\begin{array}{l}\text { decoction, powder, } \\
\text { fresh juice }\end{array}$ & cold, fever, flu, bronchitis \\
\hline $\begin{array}{l}\text { Peganum } \\
\text { harmala }\end{array}$ & Esphand & zygophyllaceae & seed & soaked eaten & $\begin{array}{c}\text { respiratory and nervous system diseases, cough, } \\
\text { stomachache }\end{array}$ \\
\hline $\begin{array}{l}\text { Punica } \\
\text { granatium }\end{array}$ & Anar & Punicaceae & peel & cooked raw & $\begin{array}{l}\text { antibiotic, urinary tract infections, anti- } \\
\text { inflammation, cold, flu }\end{array}$ \\
\hline Rosa canina & Nastaran & Rosaceae & fruit & decoction & preventive for flu \\
\hline $\begin{array}{l}\text { Berberis } \\
\text { vulgaris }\end{array}$ & Zereshk & Berberidaceae & fruit & decoction & dysentery, sedative, malaria, anti-inflammatory \\
\hline Digitalis sp. & Angoshtane & Scrophulariaceae & Leaf & $\begin{array}{l}\text { fresh water of Leaf, } \\
\text { liquid extract }\end{array}$ & $\begin{array}{l}\text { anti-inflammatory, anti-oxidant, antipyretic, } \\
\text { antirheumatic, stimulatory forthe immune system }\end{array}$ \\
\hline
\end{tabular}


impregnated-disk was indicative of the inhibitory effects. The diameter of the zone of inhibition around each of the disks was measured and recorded. Each experiment was performed in triplicates.

\subsection{Measurement of Vitamin C}

The concentration of vitamin $C$ in each extractwas measured using the colorimetric method (19). In short, $0.2 \mathrm{~g}$ of vitamin C powder as the standard and $500 \mu \mathrm{L}$ of the stock solutions of each plant extract were mixed with metaphosphoric acid 6g/dL and centrifuged at $3000 \mathrm{rpm}$ for 10 minutes. Next, $1.2 \mathrm{~mL}$ of the supernatant from each of the tubes were combined with a mixture containing copper sulphate $0.6 \%$, thiourea $5 \%$ and diphenyl hydrazine $2 \%$. After three hours of incubationin a water bath at $37^{\circ} \mathrm{C}, 2 \mathrm{~mL}$ of sulphuric acid $12 \mathrm{M}$ was added to each tube. The content of vitamin $C$ in each sample was measured by reading the absorbance in a spectrophotometer at OD of $520 \mathrm{~nm}$. This experiment was carried out in duplicates.

\section{Results}

\subsection{Anti M. tuberculosis Activity}

Amongst the hydro-alcoholic extracts of the six selected medicinal plants, fruit extracts of Berberis vulgaris and Rosa canina showed no inhibitory activity against Myco- bacterium tuberculosis. Extract of Punica granatum even at concentration of $25 \mathrm{mg} / \mathrm{mL}$ could prevent the growth of all M. tuberculosis isolates while the extract of Peganum harmalahad this property ata concentration of $50 \mathrm{mg} / \mathrm{mL}$ (Table 2). Ethanolic extract of Citrus lemon could prevent the growth of non-MDR Mycobacterium tuberculosis isolates while theethanolic extract of Digitalis sp. showed a mild anti-M. tuberculosis activity at concentrations of 200 and $100 \mathrm{mg} / \mathrm{mL}$. Isoniazid and rifampin showed inhibitory effects only against non-MDR M. tuberculosis isolates. The zone of growth inhibition and the number of isolates which showed inhibitory effects were decreased with decreasing concentrations of ethanolic extracts, so that Citrus lemon extract at concentration of 200 and $25 \mathrm{mg} /$ $\mathrm{mL}$ inhibited the growth of four and one M. tuberculosis isolates, respectively. Although, ethanolic extract of Digitalis sp. at a concentration of $200 \mathrm{mg} / \mathrm{mL}$ could inhibit the growth of five M.tuberculosis isolates, none of isolates were inhibited at a concentration of $50 \mathrm{mg} / \mathrm{mL}$ (Table 2).

Anti-TB activity was shown by extracts of Punica granatum and Peganum harmala on sensitive and resistant strains of Mycobacterium tuberculosis. The maximum zone of inhibition against an MDR strain was observed with extract of Punica granatum $(19.5 \pm 3.5 \mathrm{~mm})$ and against a non-MDR strain by extract of Peganum harmala (19 \pm 2.6 $\mathrm{mm})$ as compared with the standard rifampin (19.5 \pm 2.4 $\mathrm{mm}$ ) and isoniazid $(19.5 \pm 2.1 \mathrm{~mm})$.

Table 2. Anti-Tuberculosis Activity of Selected Medicinal Plants Against Multi-Drug Resistant and Non-Multi-Drug Resistant M. tuberculosis $^{\mathrm{a}}$

\begin{tabular}{|c|c|c|c|c|c|c|c|c|c|}
\hline \multirow[t]{2}{*}{ Concentrations, $\mathrm{mg} / \mathrm{mL}$} & \multirow[t]{2}{*}{ H37RV } & \multirow[t]{2}{*}{$\mathrm{MDR}_{1}$} & \multirow[t]{2}{*}{$\mathrm{MDR}_{2}$} & \multirow[t]{2}{*}{ Non $M_{1} R_{1}$} & \multirow[t]{2}{*}{ Non $\mathrm{MDR}_{2}$} & \multirow[t]{2}{*}{ Non $\mathrm{MDR}_{3}$} & \multirow[t]{2}{*}{ Non MDR $_{4}$} & \multicolumn{2}{|c|}{ Mean } \\
\hline & & & & & & & & MDR & Non MDR \\
\hline \multicolumn{10}{|l|}{ Citrus lemon } \\
\hline 200 & 10 & $\mathrm{R}$ & $\mathrm{R}$ & 20 & 20 & $\mathrm{R}$ & 10 & $\mathrm{R}$ & $12.50 \pm 9.6$ \\
\hline 100 & $\mathrm{R}$ & $\mathrm{R}$ & $\mathrm{R}$ & 15 & 15 & $\mathrm{R}$ & $\mathrm{R}$ & $\mathrm{R}$ & $7.50 \pm 8.7$ \\
\hline 50 & $\mathrm{R}$ & $\mathrm{R}$ & $\mathrm{R}$ & 8 & 10 & $\mathrm{R}$ & $\mathrm{R}$ & $\mathrm{R}$ & $4.50 \pm 5.3$ \\
\hline 25 & $\mathrm{R}$ & $\mathrm{R}$ & $\mathrm{R}$ & $\mathrm{R}$ & 8 & $\mathrm{R}$ & $\mathrm{R}$ & $\mathrm{R}$ & $2.00 \pm 4.0$ \\
\hline \multicolumn{10}{|l|}{ Peganumharmala } \\
\hline 200 & 18 & 20 & 17 & 18 & 22 & 20 & 16 & $18.50 \pm 2.1$ & $19.00 \pm 2.6$ \\
\hline 100 & 15 & 16 & 15 & 15 & 15 & 15 & 12 & $15.50 \pm 1$ & $14.25 \pm 1.5$ \\
\hline 50 & 8 & 12 & 10 & 14 & 12 & 12 & 10 & $11.00 \pm 1.4$ & $12.00 \pm 1.6$ \\
\hline 25 & $\mathrm{R}$ & 10 & 8 & 12 & 8 & 10 & 9 & $9.00 \pm 1.4$ & $9.75 \pm 1.7$ \\
\hline \multicolumn{10}{|l|}{ Punicagaranatium } \\
\hline 200 & 20 & 22 & 17 & 18 & 15 & 18 & 20 & $19.50 \pm 3.5$ & $17.75 \pm 2.1$ \\
\hline 100 & 17 & 18 & 13 & 15 & 13 & 15 & 16 & $15.50 \pm 3.5$ & $14.75 \pm 1.3$ \\
\hline 50 & 15 & 15 & 10 & 13 & 10 & 14 & 13 & $12.50 \pm 3.5$ & $12.50 \pm 1.7$ \\
\hline 25 & 13 & 10 & 8 & 10 & 8 & 10 & 8 & $9.00 \pm 1.4$ & $9.00 \pm 1.2$ \\
\hline \multicolumn{10}{|l|}{ Digitalis Sp. } \\
\hline 200 & $\mathrm{R}$ & $\mathrm{R}$ & 12 & 12 & 12 & 12 & 14 & $6.00 \pm 6$ & $12.50 \pm 1$ \\
\hline 100 & $\mathrm{R}$ & $\mathrm{R}$ & $\mathrm{R}$ & 10 & 10 & 10 & 10 & $\mathrm{R}$ & 10 \\
\hline 50 & $\mathrm{R}$ & $\mathrm{R}$ & $\mathrm{R}$ & $\mathrm{R}$ & $\mathrm{R}$ & $\mathrm{R}$ & $\mathrm{R}$ & $\mathrm{R}$ & $\mathrm{R}$ \\
\hline 25 & $\mathrm{R}$ & $\mathrm{R}$ & $\mathrm{R}$ & $\mathrm{R}$ & $\mathrm{R}$ & $\mathrm{R}$ & $\mathrm{R}$ & $\mathrm{R}$ & $\mathrm{R}$ \\
\hline \multicolumn{10}{|l|}{ Isoniazid, $\mu \mathrm{g} / \mathrm{mL}$} \\
\hline 2 & 18 & $\mathrm{R}$ & $\mathrm{R}$ & 17 & 22 & 20 & 19 & $\mathrm{R}$ & $19.50 \pm 2.1$ \\
\hline \multicolumn{10}{|l|}{ Rifampin, $\mu \mathrm{g} / \mathrm{mL}$} \\
\hline 5 & 16 & $\mathrm{R}$ & $\mathrm{R}$ & 18 & 23 & 19 & 18 & $\mathrm{R}$ & $19.50 \pm 2.4$ \\
\hline
\end{tabular}

\footnotetext{
a Abbreviations: MDR, multiple-drug resistant; Non MDR, non-multiple-drug resistant.
} 
Jahanpour Set al.

\begin{tabular}{lcc}
\hline \multicolumn{3}{l}{ Table 3. Level of Vitamin $C$ of Selected Medicinal Plants } \\
\hline Name of the Plant & OD & Concentration(mg/dL) \\
\hline Punica granatum & 0.300 & 43.3 \\
\hline Digitalis sp. & 0.300 & 43.3 \\
Berberis vulgaris & 0.285 & 41.1 \\
Rosa canina & 0.145 & 20.9 \\
\hline Citrus lemon & 0.078 & 11.3 \\
\hline Peganum harmala & 0.063 & 9.1 \\
\hline
\end{tabular}

\subsection{Measurement of Vitamin C Level}

The level of vitamin $C$ in ethanolic extracts of the selected plants are presented in Table 3. Extract of Punica granatum and Digitalis sp. with vitamin C amount $43.3 \mathrm{mg} / \mathrm{dL}$ showed the maximum level of vitamin $\mathrm{C}$.

\section{Discussion}

In the present study, selection of medicinal plants was based on a previous study, conducted by Ghaemi et al. (13). The plants were used for the treatment of tuberculosis, chronic respiratory diseases or symptoms of diseases, by local healers in this area. Ghaemi et al. reported that among the 52 herbal plants examined, only six extracts had good anti-mycobacterial activity against two nonpathogenic strains of $M$. bovis BCG and M. smegmatis (13). Therefore, the present study aimed to evaluate the inhibitory effects of these six medicinal plants on the growth of Mycobacterium tuberculosis, as the most important pathogenic mycobacteria. Among these plants only the ethanolic extracts of Peganum harmala and Punica granatum showed potential inhibitory effects against $M$. tuberculosis. Similarly, Gautam et al. (20) found anti-mycobacterial activity by ethanolic extracts of $P$. harmala and P. granatum. Also Ghaemi et al. showed that ethanolic extracts of $P$. granatum have greater effects on $M$. bovis compared to M. smegmatis. Pomegranate is an edible fruit, which natively grows in Iran and many studies have been done on its biological properties that confirm the therapeutic properties of this plant. Pomegranate has a wide range of bioactive compounds such as: alkaloids, ellagic acid, Punicalagin, ellagitannins, anthocyanin, flavonoids and tannins. Due to presence of these compounds it has various pharmacological activities such as, antioxidant, antimicrobial and anti-virus (21) and has been used to treat respiratory diseases (22). In addition to its antibacterial activities against Escherichia coli (23) and Staphylococcus aureus (24), we found that the peel extracts of pomegranate have a great potential to be used as anti-TB agents. The ethanolic extract of Peganum harmala followed by the extract of Punica granatum showed strong anti-TB activity against $M$. tuberculosis. In two studies, conducted by Gautam et al. and Ghaemi et al. it was demonstrated that theethanolic extract of this plant was active against M. smegmatis $(13,20)$ and M. bovis (13). Peganum harmala is known as "Espand" in Iran (25) and has been used traditionally in Turkey, Iran and China to treat coughs, rheu- matism, high blood pressure, diabetes and asthma (26). The seed and root extracts of $P$. harmala have broad antibacterial activity against gram-positive and negative-bacteria (25). The most pharmacological active compounds of $P$. harmala are alkaloids (27). Ghaemi et al. reported that ethanolic extracts of Citrus lemon have strong inhibitory activity against $M$. smegmatis but limited inhibitory activity on M. bovis. In another study, Kirbaslar et al. (28) showed that Citrus lemon peel oil was active against $M$. phlei and M. smegmatis,as indicated by the disk diffusion assay with an inhibitory zone equal to $13 \mathrm{~mm}$. Saeed et al. (29) reported that Citrus lemon juice had antibacterial activity against a range of gram-positive and negative bacteria. Citrus lemon has been used traditionally as an antiinflammatory, antiseptic, expectorant and relaxingagent (13). In the present study we found that this extract has moderate activity against $M$. tuberculosis. Thus, high concentrations of this extract may be effective in controlling the growth of M. tuberculosis. It is interesting to note that the extract of Citrus lemon only showed inhibitory activity against isoniazid and rifampin-sensitive isolates. Citrus lemon is a native plant of India that belongs to the Rutaceae family and is widely cultivated in Iran including the Golestan province, located north of Iran. Anti-bacterial, anti-fungal, anti-viral, anti-cancer and anti-diabetic activity of this plant is due to the presence of flavonoids and alkaloids in its crude extracts (30). Similar to the results obtained by Ghaemi et al. (13), in this study, we found weak activity for ethanolic extracts of Digitalis sp. against M. tuberculosis, therefore in vitro anti-tuberculosis activity of this plant is not remarkable. This plant may be effective in other ways, such as boosting the immune system to inhibit the growth of TB in the body. Recently, potential activity of vitamin $C$ has been shown to be part of the dramatic killing of sensitive and resistant strains of $M y$ cobacterium tuberculosis in vitro (11). Narwadiya et al. (31) supports the fact that as the concentration of vitamin C increases in plant extracts there is evidence of decrease in the number of tubercle bacilli; a claim that is some what confirmed by our result. Our findings demonstrated that Punica granatum (peel) has a high concentration of vitamin $C$ and showed maximum activity against $M$. tuberculosis, yet Digitalis sp. (leaf) although it has a high concentration of vitamin C, it did not show anti-tuberculosis activity. On the other hand, Peganum harmala (seed) had the minimum concentration of Vitamin C among all examined plants of this study, yet it showed potential activity against the tubercle bacilli. Therefore, vitamin $\mathrm{C}$ by itself is not sufficient for the inhibitory effect of extracts of medicinal plants against $M$. tuberculosis. The reason behind these observations needs further investigations. The peel of ethanolic extracts of Punica granatum and the seed extracts of Peganum harmala exhibited significant inhibitory activity in vitro. According to our findings, we can conclude that the high concentration of vitamin C in the $P$. granatum extract can justify its anti-tuberculosis effect. On the other hand, P. harmala extract does not 
contain enough vitamin $C$, thus it may contain other phytochemical constituents that contribute to the antituberculosis effects in this plant. These medicinal plants as promising candidates and may be used as novel natural products without any side effects for new anti-TB drug discovery. The application of these two extracts either in cell culture or animal models is recommend, to evaluate their growth inhibitory effects on $M$. tuberculosis.

\section{Acknowledgements}

We thank the management of the Medicinal Plants Department of Islamic Azad University of Gorgan. Also, we are grateful for the assistance of Mrs M. Tazike and Mrs S. Rahimialang, the experts at the mycobacteriology laboratory of Golestan University of Medical Sciences and the Deputy of Health for providing the necessary facilities to carry out this research. Furthermore great thanks to Mis Fatemeh Shakeri and Naemeh Javid for their kindly cooperation.

\section{Authors' Contributions}

Shadi Jahanpour: MSc student, doing experimental work and manuscript preparation; Kiumars Ghazisaidi: scientific advisor; Homa Davoodi; technical advisor; Maesoumeh Mazandarani, cooperation in collecting and identifying the herbal medicine and extracts preparation; Motahare Samet, cooperation in extract preparation; Nadia Jahanpour, cooperation in collecting herbal medicine; Ezzat Allah Ghaemi, director of the research project and corresponding author.

\section{Financial Disclosure}

This proposal was confirmed by Deputy of Research and Technology with this letter number; 35/1925, 28/09/2011.

\section{Funding/Support}

This study was financially supported by Infectious Disease Research Center, Deputy of Research and Technology, Golestan University of Medical Sciences Gorgan, Iran.

\section{References}

1. Grange JM, Zumla A. The global emergency of tuberculosis: what is the cause? JR Soc Promot Health. 2002;122(2):78-81.

2. Crane LR. History of Tuberculosis.; 2013.

3. World Health Organization. Global tuberculosis programme. Global tuberculosis control. WHO; 2011. Available from: http://www. who.int/gtb/publications.

4. Dye C, Scheele S, Dolin P, Pathania V, Raviglione MC. Consensus statement. Global burden of tuberculosis: estimated incidence, prevalence, and mortality by country. WHO Global Surveillance and Monitoring Project. JAMA. 1999;282(7):677-86.

5. Zhang Y, Yew WW. Mechanisms of drug resistance in Mycobacterium tuberculosis. Int J Tuberc Lung Dis. 2009;13(11):1320-30.

6. Blumberg HM, Burman WJ, Chaisson RE, Daley CL, Etkind SC, Friedman LN, et al. American Thoracic Society/Centers for Disease Control and Prevention/Infectious Diseases Society of America: treatment of tuberculosis. Am J Respir Crit Care Med. 2003;167(4):603-62.
7. World Health Organization. Global tuberculosis control: epidemiology, strategy, financing. WHO; 2009. Available from: http://www. who.int/tb/publications/global_report/2009/pdf/full_report. pdf.

8. Newman DJ, Cragg GM, Snader KM. Natural products as sources of new drugs over the period 1981-2002. J Nat Prod. 2003;66(7):1022-37.

9. Newman DJ, Cragg GM, Snader KM. The influence of natural products upon drug discovery. Nat Prod Rep. 2000;17(3):215-34.

10. Windisch W, Schedle K, Plitzner C, Kroismayr A. Use of phytogenic products as feed additives for swine and poultry. J Anim Sci. 2008;86(14 Suppl):E140-8.

11. Vilcheze C, Hartman T, Weinrick B, Jacobs WR, Jr. Mycobacterium tuberculosis is extraordinarily sensitive to killing by a vitamin C-induced Fenton reaction. Nat Commun. 2013;4:1881.

12. World Health Organization. Global tuberculosis programme Global tuberculosis control. WHO; 2011. Available from: http://www. who.int/gtb/publications.

13. Antimycobacterial activity of some medicinal plants used in traditional medicine in North of Iran. In: Ghaemi EA, Mazandarani M, Mansourian AR, Babaii Kochaksaraeii M editors. Proceedings of International Conference on Life Science and Technology. 2011 Iran.

14. Alade PI, Irobi ON. Antimicrobial activities of crude leaf extracts of Acalypha wilkesiana.J Ethnopharmacol.1993;39(3):171-4.

15. Chaturvedi V, Dwivedi N, Tripathi RP, Sinha S. Evaluation of Mycobacterium smegmatis as a possible surrogate screen for selecting molecules active against multi-drug resistant Mycobacterium tuberculosis. J Gen Appl Microbiol. 2007;53(6):333-7.

16. Ahmad I, Beg AZ. Antimicrobial and phytochemical studies on 45 Indian medicinal plants against multi-drug resistant human pathogens. J Ethnopharmacol. 2001;74(2):113-23.

17. Japoni Nejad A, Sofian M, van Belkum A, Ghaznavi Rad E. Nosocomial Outbreak of Extensively and Pan Drug-Resistant Acinetobacter baumanniiin Tertiary Hospital in Central Part of Iran. Jundishapur J Microbiol. 2013;6(8).

18. Molina-Salinas GM, Ramos-Guerra MC, Vargas-Villarreal J, Mata-Cardenas BD, Becerril-Montes P, Said-Fernandez S. Bactericidal activity of organic extracts from Flourensia cernua DC against strains of Mycobacterium tuberculosis. Arch Med Res. 2006;37(1):45-9.

19. Tietz NW, Burtis CA, Ashwood ER. Tietz textbook of clinical chemistry. Philadelphia: Saunders; 1994.

20. Gautam R, Saklani A, Jachak SM. Indian medicinal plants as a source of antimycobacterial agents. J Ethnopharmacol. 2007;110(2):200-34.

21. Jasuja ND, Saxena R, Chandra S, Sharma R. Pharmacological Characterization and Beneficial Uses of Punica granatum. Asian J Plant Sci. 2012;11(6):251-67.

22. Khan AJ, Hanee S. Antibacterial properties of Punica granatum peels. Int J Appl Biol Pharm Technol. 2011;2(3):23-7.

23. Voravuthikunchai SP, Sririrak T, Limsuwan S, Supawita T, Iida T, Honda T. Inhibitory effects of active compounds from Punica granatum pericarp on verocytotoxin production by enterohemorrhagic Escherichia coli O157: H7. J Health sci. 2005;51(5):590-6.

24. Machado TB, Pinto AV, Pinto MC, Leal IC, Silva MG, Amaral AC, et al. In vitro activity of Brazilian medicinal plants, naturally occurring naphthoquinones and their analogues, against methicillin-resistant Staphylococcus aureus. Int J Antimicrob Agents. 2003;21(3):279-84.

25. Darabpour E, Motamedi H, Poshtkouhian Bavi A, Seyyed Nejad SM. Eldorado Resources for and from Research Teaching and Studying.; 2011.

26. Shao H, Huang X, Zhang Y, Zhang C. Main alkaloids of Peganum harmala L. and their different effects on dicot and monocot crops. Molecules. 2013;18(3):2623-34.

27. Asgarpanah J, Ramezanloo F. Chemistry, pharmacology and medicinal properties of Peganum harmala L. Afr J Pharm Pharmacol. 2012;6(22):1573-80.

28. Kirbaslar GF, Tavman A, Dulger B, Turker G. Antimicrobial activity of Turkish citrus peel oils. PakJ Bot. 2009;41(6):3207-12.

29. Saeed S, Tariq P. Effects of some seasonal vegetables and fruits on the growth of bacteria. PakJ Biol Sci. 2006;9(8):1547-51. 


\section{Jahanpour S et al.}

30. Dhanavade MJ, Jalkute CB, Ghosh JS, Sonawane KD. Study antimicrobial activity of Lemon (Citrus lemon L.) peel extract. Br J Pharmacol Toxicol. 2011;2(3):119-22.
31. Narwadiya SC, Sahare KN, Tumane PM, Dhumne UL, Meshram VG. In vitro anti-tuberculosis effect ofvitamin $C$ contents of medicinal plants. Asian J Exp Biol Sci. 2011;2(1):151-4. 